\title{
Reconstruction of a long-term recovery process from pasture to forest
}

\author{
O. Wildi and M. Schütz
}

\author{
Swiss Federal Institute for Forest, Snow and Landscape Research, CH-8903 Birmensdorf, Switzerland. \\ E-mail: otto.wildi@wsl.ch,martin.schuetz@wsl.ch
}

Keywords: Minimum spanning tree, Plant-animal interactions, Secondary succession, Space-for-time substitution, Time series.

\begin{abstract}
We used space-for-time substitution to obtain a directed successional sequence for subalpine meadow vegetation in the Swiss National Park. Since human impacts (e.g., domestic animal grazing) ceased in 1914, the successional processes documented are assumed to be autogenic in nature. The data consist of 59 permanent plots spanning almost 90 years, and include many spatial replications. An initial inspection of the individual time series revealed the existence of a variety of response patterns, which are described in the literature as representing different successional types. However, a closer inspection suggested that many of these series can be superimposed, as they are part of a much longer deterministic series. Linking the individual time series proved to be challenging. A heuristic approach produced results that differed depending on initial starting conditions. We therefore derived a deterministic algorithm to produce a unique solution. The resulting sequence largely confirmed the heuristic interpretation, suggesting a trend from early successional (post-grazing) grassland to pine invasion spanning about 400 years. This timespan is valid only for the climatic conditions near the treeline, and for plant species specific to the study site. Our results suggest that the various species temporal response models described in the literature may be artifactual, representing portions of underlying Gaussian responses. The data also indicate that species assemblages may persist for several decades with only minor fluctuations, only to change suddenly for no apparent reason.
\end{abstract}

Abbreviation: SNP - Swiss National Park.

\section{Introduction}

The Swiss National Park (SNP) was created in 1914 to conserve and protect an area of subalpine and alpine habitats from adverse human impacts. In 1917, BraunBlanquet and colleagues established permanent plots in the area to investigate vegetation recovery processes following the removal of domestic cattle and sheep (BraunBlanquet et al. 1931). Stüssi (1970) continued these longterm observations and established some additional plots after 1940. Unfortunately, most of these data were never published. After the death of Stüssi in 1988, our institute was asked to analyse his material. We found approximately 150 well-documented time series, many spanning 50 years and some almost 90 years. These plots were relocated in the field using modern high-precision instruments. Collecting relevé information, usually taken at 510 year intervals, has continued to this day.

This study uses space-for-time substitution (Pickett 1989) to obtain general successional pathways for the SNP region. Earlier investigation indicated that vegeta- tion changes in the SNP were not as dramatic as were envisioned in 1914 (Stüssi 1970, Ellenberg 1988, Krüsi et al. 1995, Zoller 1995). However, the high quantity of the data and the timespan covered are important in revealing subtle characteristic changes in species cover and abundance. The data document a recovery (secondary succession) process that followed a change in land-use that began in 1914, when cattle and sheep were excluded from the region. In some areas, land use changes began much earlier: grazing intensity varied in time and space, and reforestation was already in progress by 1914 . Successional pathways resulting from these impacts are also documented by the permanent plots.

This paper focusses on the recognition of deterministic changes (Connell and Slatyer 1977, Huston and Smith 1987, McCook 1994), leading us to use the term 'succession' to describe the process. Although we recognize that "the terminology of succession is imprecise, reflecting the enormous and continuous variability of these processes in nature" (McCook 1994), our data clearly represent a typical example of secondary succession (see Glenn-Lewin 
and van der Maarel 1992), i.e., the landscape is developing towards a natural state and may eventually reach a successional endpoint (Pickett 1989). The changes expected during secondary succession are thought to be dominated by mechanisms related to species interactions (Peet 1992). Environmental conditions were of course not constant over the past 80 years, and it is known that the red deer population of the SNP has increased markedly over time (Schloeth 1972). Since deer are part of the natural ecosystem, conservation of the SNP can be considered a $169 \mathrm{~km}^{2}$ exclosure experiment.

The space-for-time approach is known to have many drawbacks in interpreting successional trends (see Pickett 1989). However, we feel that the strong documentation of spatial and temporal vegetation change in the SNP makes the data well-suited to this approach. Because the permanent plots varied in site condition, species composition, and disturbance regime, alternative successional pathways (Catellino et al. 1979) are to be expected. The objective of this study is to elucidate general patterns of vegetation change in the SNP, rather than identifying exceptional events. This follows the suggestion by Huisman et al. (1993) that the simplest patterns should be sought first.

\section{Methods}

\section{Data preparation}

Most of the data stem from investigations undertaken by Braun-Blanquet and Stüssi. We continued the time series by enumerating the relevés in the 1990's. In order to improve commensurability of the rather heterogeneous material, we proceeded as follows (Schütz et al. 1998):

- Because plot size differs considerably, we omitted plots $>300 \mathrm{~m}^{2}$. The remaining 59 plots ranged from $1 \mathrm{~m}^{2}$ to $300 \mathrm{~m}^{2}$.

- Cover-abundance values were back-transformed to percentage cover of each species using the mean cover percentages of each class of the Braun-Blanquet scale (e.g., $5 \%$ for code $1,17.5 \%$ for code 2 , $37.5 \%$ for code 3 , etc.).

- Species were merged into six groups that represent 'guilds'. These guilds accord with a classification of all relevés: procedures and a critical evaluation are presented in Schütz et al. (1998). Group names ('Aconitum', 'Deschampsia', 'Trisetum' etc.) are derived from the dominant species (Schütz et al. 1998).

- The data are adjusted to a total of $100 \%$ cover within each relevé.
- Since the objective of our analysis was to derive a relative time scale for vegetation change, we relied on the absolute time scale given from observations in the permanent plots. All series were adjusted so that the relevés represented five-year states, i.e., 1915, 1920, 1925, ... , 1995 (e.g., 1918, 1919, 1921 and 1922 were adjusted to 1920). In some cases, this procedure resulted in missing time-steps: these were filled using linear interpolation.

These adjustments to the data (e.g., conversion to guilds, adjustment of time-scales) necessarily resulted in some loss and possible distortion of information. We view these adjustments as conservative measures that minimize the possibility of over-interpreting the results.

\section{Data screening}

Previous studies revealed that the plots reflect different stages in a general successional pattern (Krüsi et al. 1995, 1998, Schütz et al. 1998). This was apparent during the data screening process: species composition observed in the 'early' stages of some plots was quite similar to that in more 'developed' phases observed in others. A visualization of the resemblance pattern of the entire set of relevés based on principal co-ordinates analysis revealed a striking gradient in two-dimensional ordination space, recognized even though there is an arched arrangement of points (Fig. 1, upper graph). This suggests that given sufficient temporal overlap in the data, it may be possible to synchronize spatially separated observations so as to fit a long time series. Inclusion of the third ordination axis did not provide extra information: the points follow, with some noise, the third-order polynomial function observed when there is a strong one-dimensional background gradient (Fig. 1, lower graph). We therefore attempted to derive a temporal sequence using heuristic as well as deterministic approaches.

\section{Heuristic approach}

In the heuristic approach, a 'leader' plot (Späth 1977, Schütz et al. 1998) must be defined. Starting from this, another time series with sufficient overlap is chosen for synchronisation. An example is given in Table 1. Here, plot Ac1 is taken as the 'leader' in the series. It documents $n_{1}=16$ time steps between 1920 and 1995. The remaining data sets are screened for the most similar relevés, based on the similarity ratio:

$$
s=\frac{\sum_{i} x_{A i} x_{B i}}{\sum_{i} x_{A i}^{2}+\sum_{i} x_{B i}^{2}+\sum_{i} x_{A i} x_{B i}}
$$




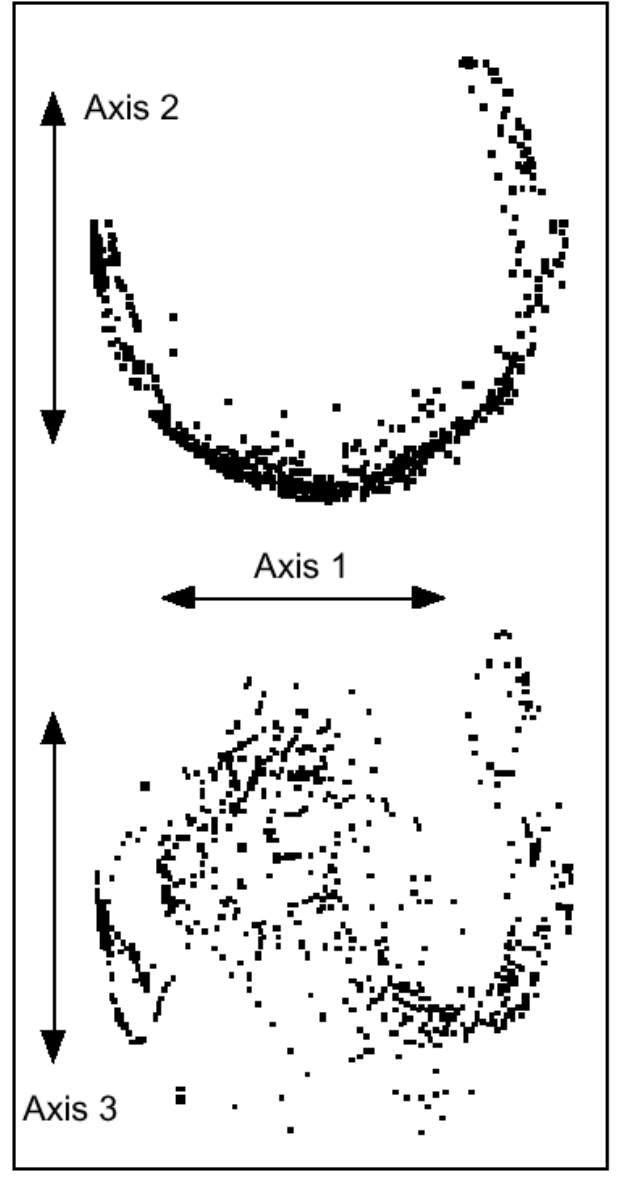

Figure 1. Principal coordinates ordination of all 751 relevés based on the six species groups as attributes.

(Wildi and Orlóci 1996). In this formula, $x_{A i}$ is the species scores in relevé $\mathrm{A}$ and $x_{B i}$ is the same in relevé $\mathrm{B}$. Summation $i$ is over all common species. For the example, plot AC9 is used as a candidate for merging, covering $n_{2}$ $=14$ time steps between 1915 and 1982. Then, a rectangular similarity matrix $\mathbf{S}$ (n1xn2) comparing all relevés of the first series (AC1) with all of the second series (AC9) is calculated. The position of the smallest element in $\mathbf{S}$ indicates the best solution for overlaying the two series. In Table 1, the closest relevés are those from 1990 in AC1 and 1959 in AC9 (shaded column in Table 1). In the resulting series $\mathrm{AC} 1 / 9$, average cover values are taken where no overlap exists.

The artificially generated time series is taken as a basis for evaluating further series as candidates for fusions (Schütz et al. 1998). These authors found that the results often depend on the choice of the leader series. A solution to this problem is based on consensus analysis (Podani 1989). Here, the different results are overlapped and a series representing the average of six different attempts is accepted. An example is given in Fig. 2. As discussed later, this particular solution reveals a time series stretching over 585 years and it exhibits several drastic vegetation changes.

\section{Deterministic solution}

The deterministic solution relies on the nearest neighbour approach when merging time series (Orlóci 1978). To accomplish this, the distance between time series must be defined. We assume that taking the resemblance of the most similar relevés in any two series will approach this. In order to rely on a metric concept, Euclidean distance was used:

$e=\left[\sum_{i}\left(x_{A i}^{\prime}-x_{B i}^{\prime}\right)^{2}\right]^{1 / 2}$

The symbols have the same meaning as in formula (1). A square-root transformation of the cover percentages was used to achieve a more qualitative view of relevé resemblance (a similar transformation is intrinsically used in the similarity ratio).

This procedure results in a 59x59 distance matrix (59 $=$ number of time series analysed), each element of which measures the nearest distance between two time series. This matrix was subjected to a minimum spanning tree analysis (Gower and Ross 1969, Legendre \& Legendre 1998). The minimum spanning tree is used to merge pairs of series in order to obtain a single shortest path. In our approach, the allocation of all individual time series within the new, artificial series is first defined through the minimum spanning tree. Only in the final step are all series averaged to obtain the complete successional pattern.

\section{Results}

The deterministic algorithm described above yields a minimum spanning tree that shows neighbourhood relationships among the 59 time series (Fig. 3). The analysis of each overlap (see Table 1) results in an arrangement of all series, which is shown graphically in Fig. 4. This graph also exhibits the number of observations contributing to the description of the various successional states. As many as five series document the beginning of the succession, i.e., plots 3, 11, 20, 40 and 51. Data density is rather high until time step 45 , but only a few series document the last stages of succession, i.e., plots 45 and 46.

The overall succession series emerging from the deterministic analysis is summarized in Fig. 5. While it basically confirms the heuristic interpretation (Fig. 2), the most pronounced difference lies in the length of the series. 
Table 1 . Example for merging of two time series (AC1 and AC9) into one new (AC1/9). The scores in AC1/9 are the mean cover percentages of the corresponding states in AC1 and AC9 respectively. The shaded column contains the most similar relevés of the two series.

\begin{tabular}{|l|c|c|c|c|c|c|c|c|c|c|c|c|c|c|c|c|c|}
\hline Plot AC1 & & & & & & & & & & & & & & & & & \\
\hline Year 19.. & 30 & 35 & 42 & 47 & 53 & 57 & 60 & 65 & 68 & 74 & 81 & 85 & 90 & 94 & & & \\
\hline "Aconitum" & 72 & 71 & 70 & 56 & 44 & 26 & 48 & 40 & 34 & 31 & 24 & 23 & 22 & 22 & & & \\
\hline "Deschampsia" & 18 & 19 & 21 & 27 & 38 & 46 & 40 & 42 & 44 & 46 & 51 & 54 & 58 & 60 & & & \\
\hline & 8 & 7 & 6 & 9 & 7 & 14 & 7 & 9 & 11 & 13 & 12 & 11 & 9 & 8 & & & \\
\hline & & & & & & & & & & & & & & & & & \\
\hline Plot AC9 & & & & & & & & & & & & & & & & & \\
\hline Year 19.. & & & & 17 & 22 & 25 & 32 & 35 & 40 & 47 & 50 & 53 & 59 & 65 & 68 & 74 & 82 \\
\hline "Aconitum" & & & & 85 & 86 & 86 & 85 & 72 & 57 & 39 & 33 & 25 & 23 & 16 & 29 & 24 & 16 \\
\hline "Deschampsia" & & & & 12 & 10 & 12 & 14 & 22 & 32 & 40 & 43 & 46 & 55 & 57 & 47 & 49 & 46 \\
\hline "Trisetum" & & & & 3 & 3 & 1 & 0 & 2 & 5 & 7 & 9 & 10 & 8 & 11 & 11 & 11 & 15 \\
\hline & & & & & & & & & & & & & & & & & \\
\hline Plot AC1/9 & & & & & & & & & & & & & & & & & \\
\hline Year. & 0 & 5 & 10 & 15 & 20 & 25 & 30 & 35 & 40 & 45 & 50 & 55 & 60 & 65 & 70 & 75 & 80 \\
\hline "Aconitum" & 72 & 71 & 70 & 70 & 65 & 56 & 67 & 56 & 45 & 35 & 28 & 24 & 23 & 19 & 29 & 24 & 16 \\
\hline "Deschampsia" & 18 & 19 & 21 & 20 & 24 & 29 & 27 & 32 & 38 & 43 & 47 & 50 & 56 & 58 & 47 & 49 & 46 \\
\hline "Trisetum" & 8 & 7 & 6 & 6 & 5 & 8 & 3 & 6 & 8 & 10 & 10 & 11 & 9 & 10 & 11 & 11 & 15 \\
\hline
\end{tabular}

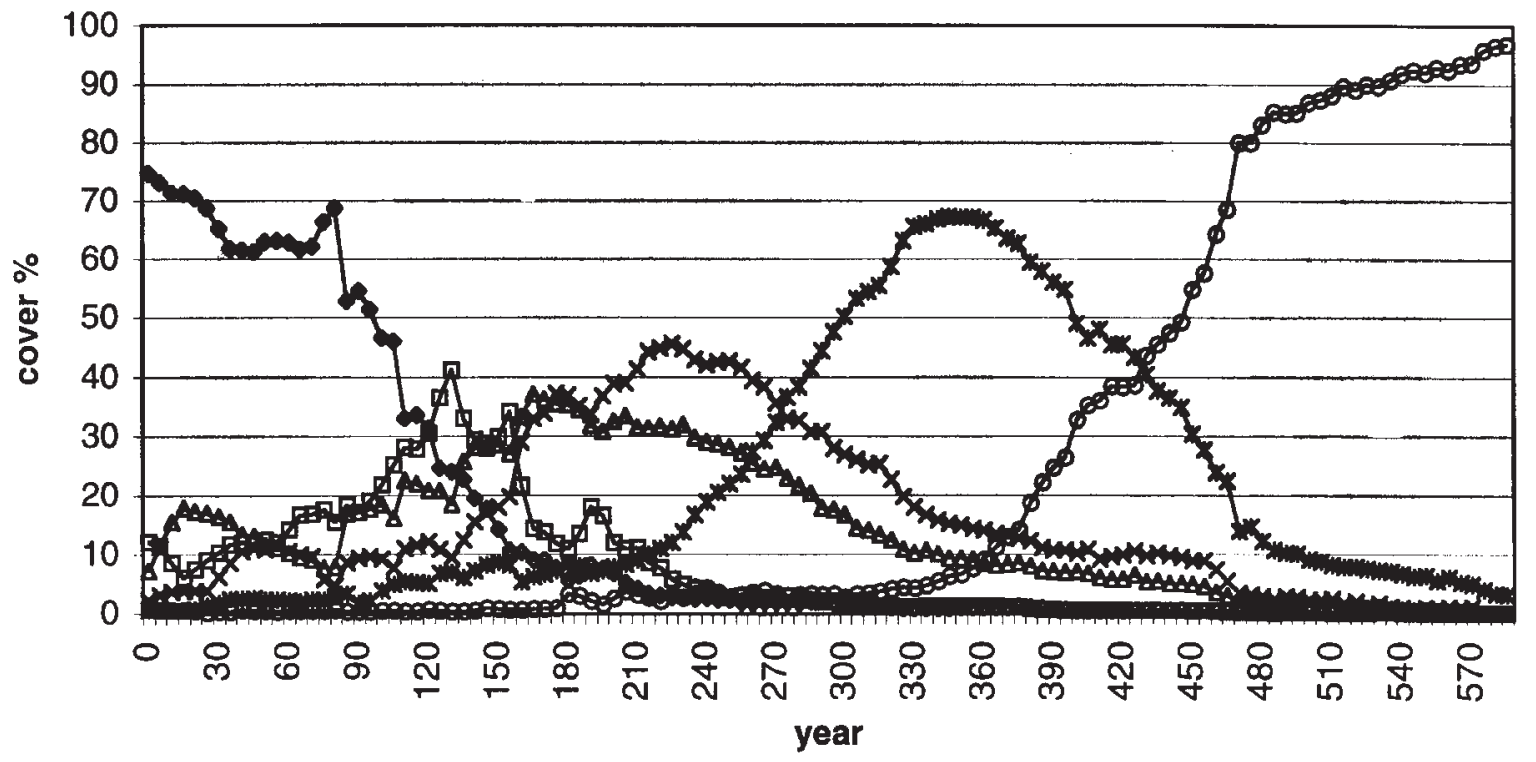

Figure 2. Time series of results from 59 permanent plots composed by the heuristic approach (Schütz et al. 1998). 


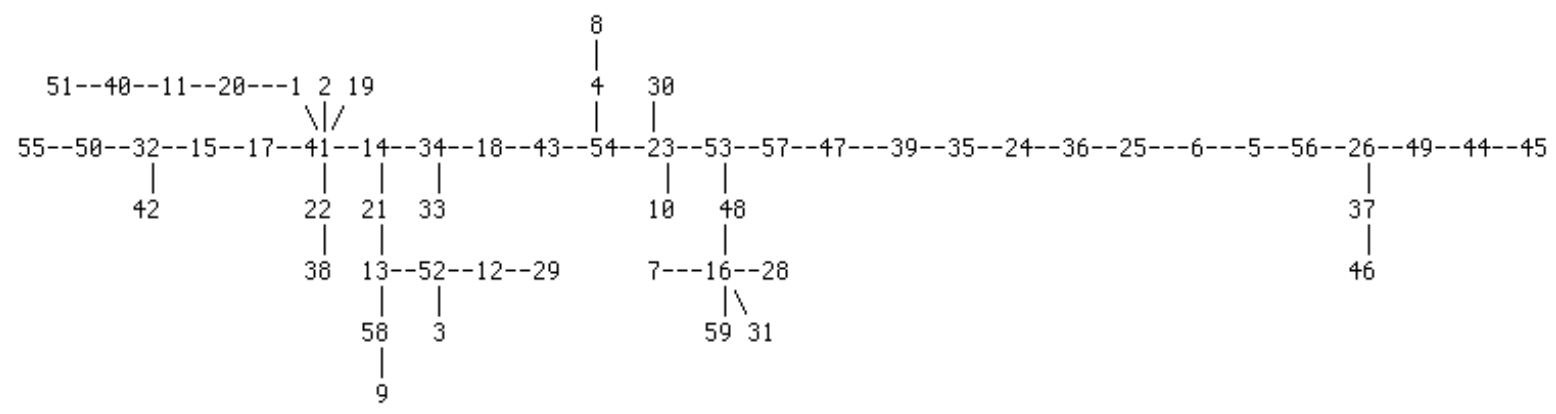

Figure 3. The minimum spanning tree topology of 59 time series.

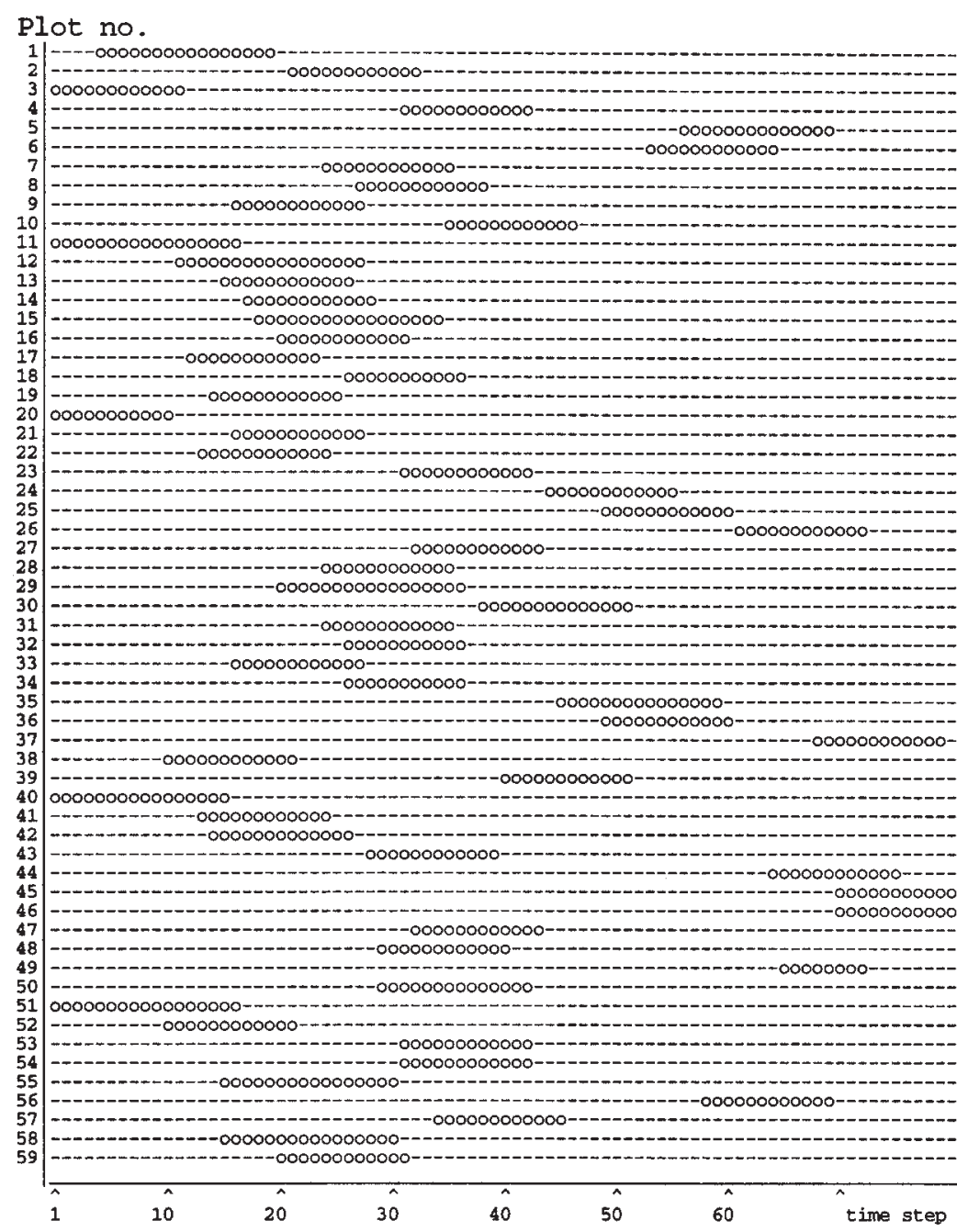

Figure 4. Position of all 59 time series within the synthetic time scale of 81 time steps.

Whereas the heuristic solution suggests a time span of 585 years (i.e., 117 time intervals), the deterministic one suggests 405 years (i.e., 81 time intervals). This is not surprising, since the minimum spanning tree seeks the shortest possible solution from the time series resemblance matrix. The deterministic result can thus be viewed as the most parsimonious solution with respect to time.
The deterministic and heuristic approaches revealed the same overall successional trends. An initial 'Aconitum' phase, resulting of livestock grazing and fertilization, dominates for about 50 years after the cessation of grazing. A 'Deschampsia' phase then emerges and is dominant for about 15 years. A later transition to a grassland dominated by Festuca rubra may be the result of 


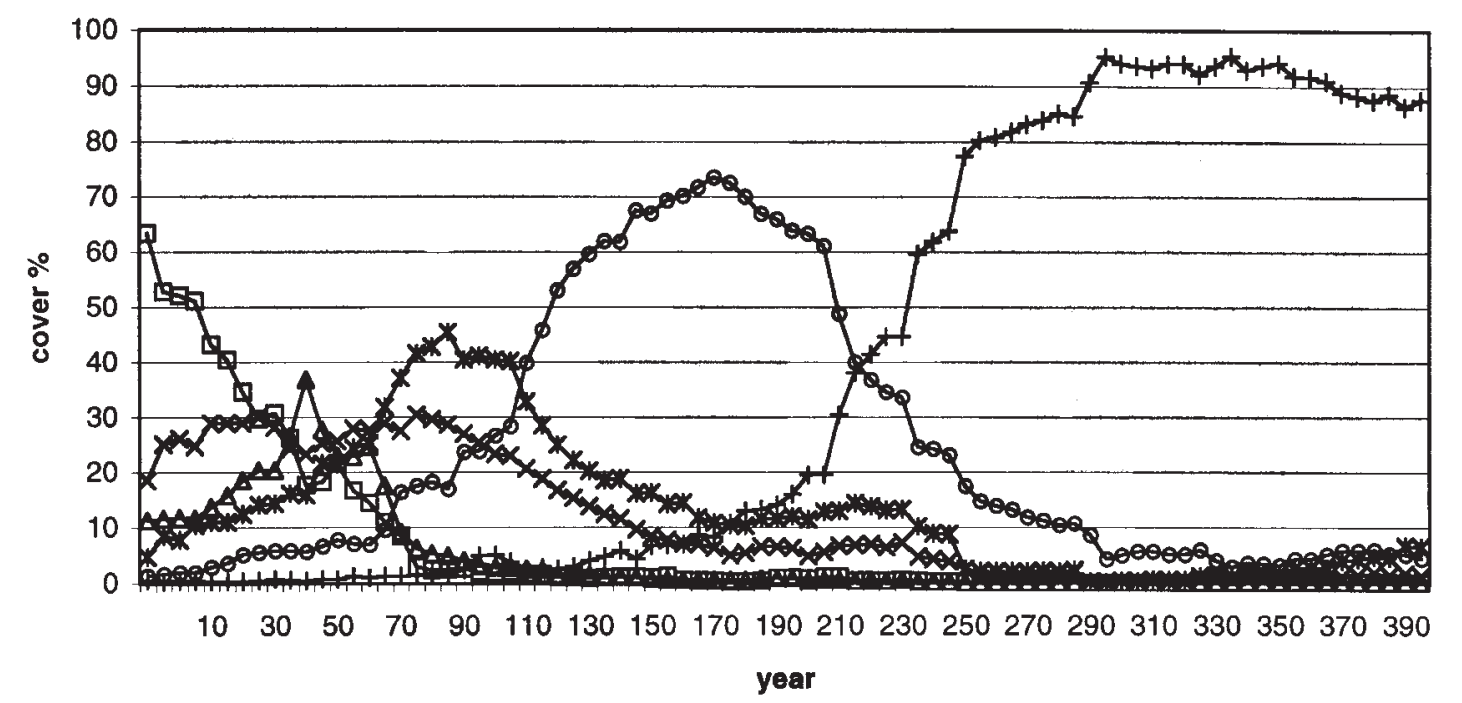

\begin{tabular}{ll|}
$\rightarrow-$ Aconitum & - Deschampsia \\
- Trisetum & $\rightarrow$ Festuca \\
$\rightarrow$ Carex & + Pinus \\
\hline
\end{tabular}

Figure 5. The minimum spanning tree-based solution for a synthetic time series of the recovery.

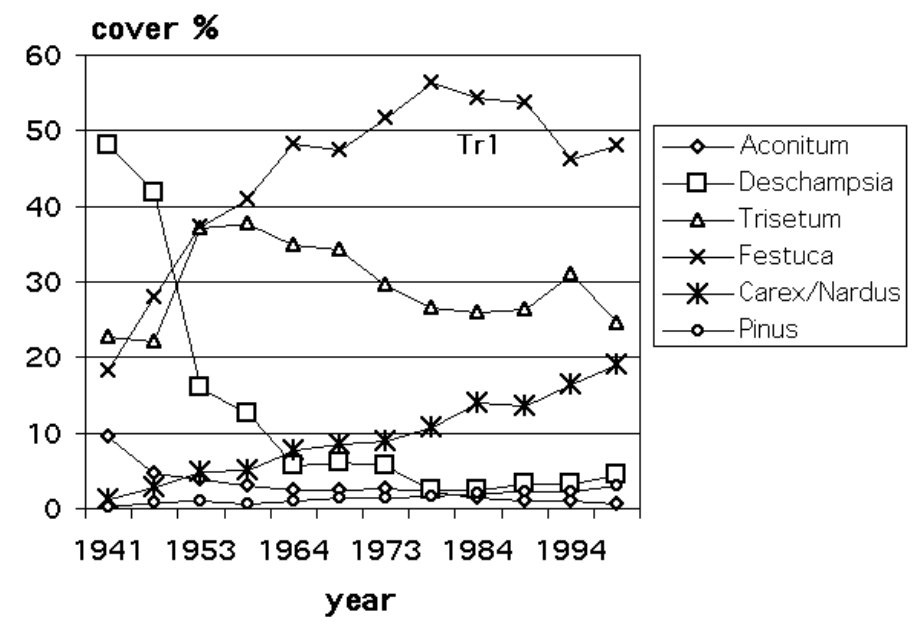

Figure 6. Types of successional patterns observed in plot $\operatorname{Tr} 1$.

grazing activity by red deer (Ellenberg 1988, Achermann et al. 1999). This is followed by a 'Carex' phase that may last for 150 years. Finally, Pinus montana seedlings begin to establish, initiating the reforestation phase.

\section{Discussion}

Long-term observations are required to distinguish between cyclical fluctuations and directed successions (van Andel et al. 1993). A directed succession implies that species replacements are the result of one or more underlying mechanistic processes. Unfortunately, the term 'mechanism' is defined variously in the literature (Bur- rows 1990), and some confusion may result by failing to distinguish between causes and mechanisms (van Andel et al. 1993). The time series analysis undertaken here is primarily an exercise in pattern recognition: the demonstrated temporal trends are assumed to stem from underlying processes.

Species responses over time can be classified according to a set of prototypes (Huisman et al. 1993). When screening the data from the SNP, it is easy to detect all of these prototypes. Indeed, most responses can be observed within a single plot: $\operatorname{Tr} 1$ is an example (Fig. 6). Here 'Festuca' has a bell-shaped response, while 'Trisetum' ap- 
pears to display a bimodal response. 'Deschampsia' decreases asymptotically, while 'Carex' increases linearly, and 'Pinus' remains constant at a low level. However, when considered over a longer timespan these patterns turn out to be fragments of bell-shaped functions (Fig. 5). This suggests that the recognition of different successional patterns is simply temporally scale-dependent.

Our results suggest that changes in species composition may proceed slowly or quickly, implying that interpretation of the time-scale is not trivial. The use of observed time steps can thus be seen as a surrogate to a hypothetical time unit representing change. It would of course be possible to adjust the different time series such that they exhibit the same rate of change per time unit. However, in doing so one looses the connection to the time scale as a means of measuring the speed of the process. Ideally, one would find a method for measuring the reliability of the temporal scale. But while absolute dating is possible in the case of fossil records, no corrresponding method exists in successional studies.

The results presented assume a deterministic succession, but Fig. 1 suggests that alternative successional pathways are possible (Catellino et al. 1979). These cannot be detected directly using the algorithms described here. Visually, alternative pathways could be identified from the minimum spanning tree, but our results suggest that a single sequence dominates: all branches of the tree are short sequences, indicating that there are no directed alternatives in the series (Fig. 3). The minimum spanning tree topology should be interpreted with caution, however, since it only defines nearest neighbor relationships and may therefore not effectively summarize major trends. In particular, it should be noted that only one end of the longest sequence in Fig. 3 represents an extreme in the proposed successional sere (plot 45): 'beginning' and 'end' can only be identified by referring to Fig. 4 (plots 3, $11,20,40$ and 51 marking the beginning of the series, and plots 45 and 46 the end).

\section{Conclusion}

An important conclusion from the SNP data is that vegetation changes may occur very rapidly in some plots but extremely slowly in others. Alternatively, species assemblages may remain very stable for 40 years, and then suddenly undergo dramatic changes. The most important impact on the ecosystem is thought to be grazing pressure from red deer, but this is known to have increased gradually. We therefore conclude that the dynamics of vegetation change is autogenic and not fully predictable from environmental conditions.
Successional studies based on space-by-time substitution are expected to be more successful when the observation period is sufficiently long. Future succession studies should encompass a variety of system states, i.e., the inherent spatial variation should be sufficiently represented in the sample. At least some of the observed states may represent not ecological variants, but different successional phases. If true, only the partial space by time substitution approach will allow for the detection of very long-term successional processes.

Extreme non-linearity makes the prediction of longterm vegetation change based on short-term observations difficult. As illustrated in Fig. 6, short term patterns may be misinterpreted: this holds true not only for cyclical fluctuations, but for linear (increasing or decreasing) trends as well. What we are observing at a given location is simply a state at a given point in time (Gleason 1926). No natural system remains unchanged over a long time period, even if no discernable variables impacting the system are observed. Furthermore, short term changes that some may consider 'uninteresting' may in fact mark the beginning of a spectacular process of change.

\section{References}

Achermann, G., M. Schütz, B.O. Krüsi and O. Wildi. 1999. Longterm Vegetation Change in Tall-herb Communities. Nationalparkforschung Schweiz.

Braun-Blanquet, J., S. Brunies, E. Campell, E. Frey, H. Jenny, Ch. Meylan and H. Pallmann. 1931. Vegetationsentwicklung im Schweiz. Nationalpark. Ergebnisse der Untersuchung von Dauerbeobachtungsflächen I. Dokumente zur Untersuchung des Schweiz. Nationalparks. Jahresb. Nat. Ges. Graub. 69: 3- 82.

Burrows, C. J. 1990. Processes of Vegetation Change. Unwin, London.

Cattelino P.J., I.R. Noble, R.O. Slatyer and S.R. Kessel. 1979. Predicting the multiple pathways of plant succession. Environ Manage. 3: 41-50.

Connell J.H. and R.O. Slatyer. 1977. Mechanisms of succession in natural communities and their role in community stability and organization. Am. Nat. 111: 1119-1144.

Ellenberg, H. 1988. Vegetation Ecology of Central Europe. Cambridge University Press, Cambridge. $1^{\text {st }}$ English edition, translated from the $4^{\text {th }}$ German edition. $731 \mathrm{p}$.

Gleason H.A. 1926. The individualistic concept of the plant association. Bull. Torrey Bot. Club 53: 7-26.

Glenn-Lewin, D.C. and E. van der Maarel. 1992. Patterns and processes of vegetation dynamics. In: D. C. Glenn-Lewin, R.K. Peet and T.T. Veblen (eds.), Plant Succession. Chapman \& Hall, London. pp. 11-59.

Gower, J. C. and G.J.S. Ross. 1969. Minimum spanning tree and singe linkage cluster analysis. Appl. Stat. 18: 54-64.

Huisman, J, H. Olff and L.F.M. Fresco. 1993. A hierarchical set of models for species response analysis. J. Veg. Sci. 4: 37-46.

Huston, M. and T. Smith. 1987. Plant succession: life history and competition. Am. Nat. 130: 168-198. 
Krüsi, B. O., M. Schütz, O. Wildi and H. Grämiger. 1995. Huftiere, Vegetationsdymanik und botanische Vielfalt im Nationalpark. Ergebnisse von Langzeitbeobachtungen. Cratschla 3: 14-25.

Krüsi, B.O., M. Schütz, C. Bigler, H. Grämiger and G. Achermann. 1998. Huftiere und Vegetation im Schweizerischen Nationalpark von 1917 bis 1997. Teil 1: Einfluss auf die botanische Vielfalt der subalpinen Weiden; Teil 2: Einfluss auf das Wald-Freilandverhältnis. In: R. Cornelius und R. Hofmann (Hrsg.), Extensive Haltung robuster Haustierrassen, Wildtiermanagement, Multi-Spezies-Projekte - Neue Wege in Naturschutz und Landschaftspflege? Inst. Zoo-Wildtierforsch., Berlin, 62-74.

Legendre, P. and L. Legendre. 1998. Numerical Ecology. $2^{\text {nd }}$ ed. E1sevier, Amsterdam.

Matlack, G. R. 1994. Vegetation dynamics of the forest edge - trends in space and successional time. J. Ecol. 82: 113-123.

McCook, L. J. 1994. Understanding ecological community succession: Causal models and theories, a review. Vegetatio 110: 115147.

Orlóci, L. 1978. Multivariate Analysis in Vegetation Research. $2^{\text {nd }}$ ed. Junk, The Hague.

Peet, R. K. 1992. Community structure and ecosystem function. In: D. C. Glenn-Lewin, R.K. Peet and T.T. Veblen (eds.), Plant Succession. Chapman \& Hall. London. pp. 103-151.

Pickett, T. A. 1989. Space-for-time substitution as an alternative to long-term studies. In: E. Likens (ed.), Long-Term Studies in Ecology: Approaches and Alternatives. Springer, New York. pp. 110-135.
Podani, J. 1989. A method for generating consensus partitions and its application to community classification. Coenoses 1: 1-10.

Schloeth, R. F. 1972. Die Entwicklung des Schalenwildbestandes im Schweizerischen Nationalpark von 1918 - 1971. Schweiz. Zeitschr. Forstwes. 123: 565-571.

Schütz, M., B. O. Krüsi, G. Achermann, and H. Grämiger. 1998 Zeitreihenanalyse in der Vegetationskunde: Analyse und Interpretation von Einzelflächen am Beispiel von Daten aus dem Schweizerischen Nationalpark. Bot. Helv. 108: 105 -124.

Späth, H. 1977. Cluster-Analyse-Algorithmen zur Objektklassifizierung und Datenreduktion. $2^{\text {nd }}$ ed. Oldenburg, München, Wien. $217 \mathrm{p}$.

Stüssi, B. 1970. Naturbedingte Entwicklung subalpiner Weiderasen auf Alp La Schera im Schweizer Nationalpark während der Reservatsperiode 1939-1965. Ergebnisse der wissenschaftlichen Untersuchungen im schweizerischen Nationalpark. Bd XIII, 385 p.

Van Andel, J., J. P. Bakker and A. P. Grootjans. 1993. Mechanisms of vegetation succession: a review of concepts and perspectives. Acta Bot. Neerl. 42: 413-433.

Wildi, O. and L. Orlóci. 1996. Numerical Exploration of Community Patterns. A Guide to the Use of MULVA-5. 2nd Ed., SPB Academic Publishing bv, The Hague, 171p.

Zoller, H. 1995. Vegetationskarte des Schweizerischen Nationalparkes. Erläuterungen. Natl. Park-Forsch. Schweiz 85, 108 p. 